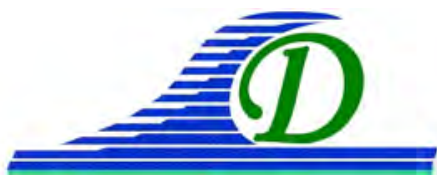

XIII ${ }^{\text {èmes }}$ Journées Nationales Génie Côtier - Génie Civil Dunkerque, 2-4 juillet 2014

DOI:10.5150/jngcgc.2014.028 C Editions Paralia CFL disponible en ligne - http://www.paralia.fr - available online

\title{
Dynamique sédimentaire dans la zone littorale de la Skhira (Golfe de Gabès, Tunisie)
}

\section{Mouldi BRAHIM ${ }^{1}$, Abdelfattah ATOUI ${ }^{1}$, Chérif SAMMARI ${ }^{1}$, Lotfi ALEYA $^{2}$}

1. Institut National des Sciences et Technologies de la Mer- Salammbô-Tunis 28, rue de 2 mars 1934, 2025 Salammbô, Tunisie. mouldi.brahim@instm.rnrt.tn

2. Université de Franche-Comté, Laboratoire de Chrono-Environnement, UMR CNRS 6249, Place Leclerc, F-25030 Besançon Cedex, France.

\section{Communication non présentée}

\section{Résumé :}

La distribution spatiale de la taille des particules dans la frange littorale de la Skhira et les vitesses et les directions des courants analysés ont permis d'avoir une vue d'ensemble sur la dynamique et le transport des sédiments dans la zone. La taille moyenne des grains de sable montre que le fond est constitué de sables fins et de sables moyens près de la côte et de sables vaseux au large. Le pourcentage de la fraction fine $(<63 \mu \mathrm{m})$ par rapport à la fraction grossière $(>63 \mu \mathrm{m})$ est plus important au large.

Les mesures réalisées à l'aide d'un ADCP ont montré que le courant principal a une direction de $60^{\circ}$ par rapport à l'est. Il a une direction sud-ouest/nord-est parallèle à la ligne de côte. La valeur de la vitesse maximale suivant l'axe principal (sud-ouest/nordest) est de l'ordre de $13 \mathrm{~cm} \mathrm{~s}^{-1}$, alors qu'elle est de l'ordre de $4.5 \mathrm{~cm} \mathrm{~s}^{-1}$ suivant l'axe mineur de direction est-ouest. La rose des courants montre que les courants parallèles à la côte sont en général faibles à modérés, mais ils peuvent dépasser $20 \mathrm{~cm} \mathrm{~s}^{-1}$.

La distribution des grains de sable a montré qu’il existe une amélioration du tri granulométrie vers le nord-est. En revanche, on n’observe pas clairement de diminution du diamètre moyen vers le large.

Mots clés : Granulométrie, Courants, Dynamique sédimentaire, Skhira, Golfe de Gabès. 
Thème 2 - Dynamique sédimentaire 
XIII ${ }^{\text {èmes }}$ Journées Nationales Génie Côtier - Génie Civil Dunkerque, 2-4 juillet 2014 
Thème 2 - Dynamique sédimentaire 
XIII ${ }^{\text {èmes }}$ Journées Nationales Génie Côtier - Génie Civil Dunkerque, 2-4 juillet 2014 
Thème 2 - Dynamique sédimentaire 
XIII ${ }^{\text {èmes }}$ Journées Nationales Génie Côtier - Génie Civil Dunkerque, 2-4 juillet 2014 
Thème 2 - Dynamique sédimentaire 